\title{
Hevesy Metal Awarded to Academician B.F. Myasoedov
}

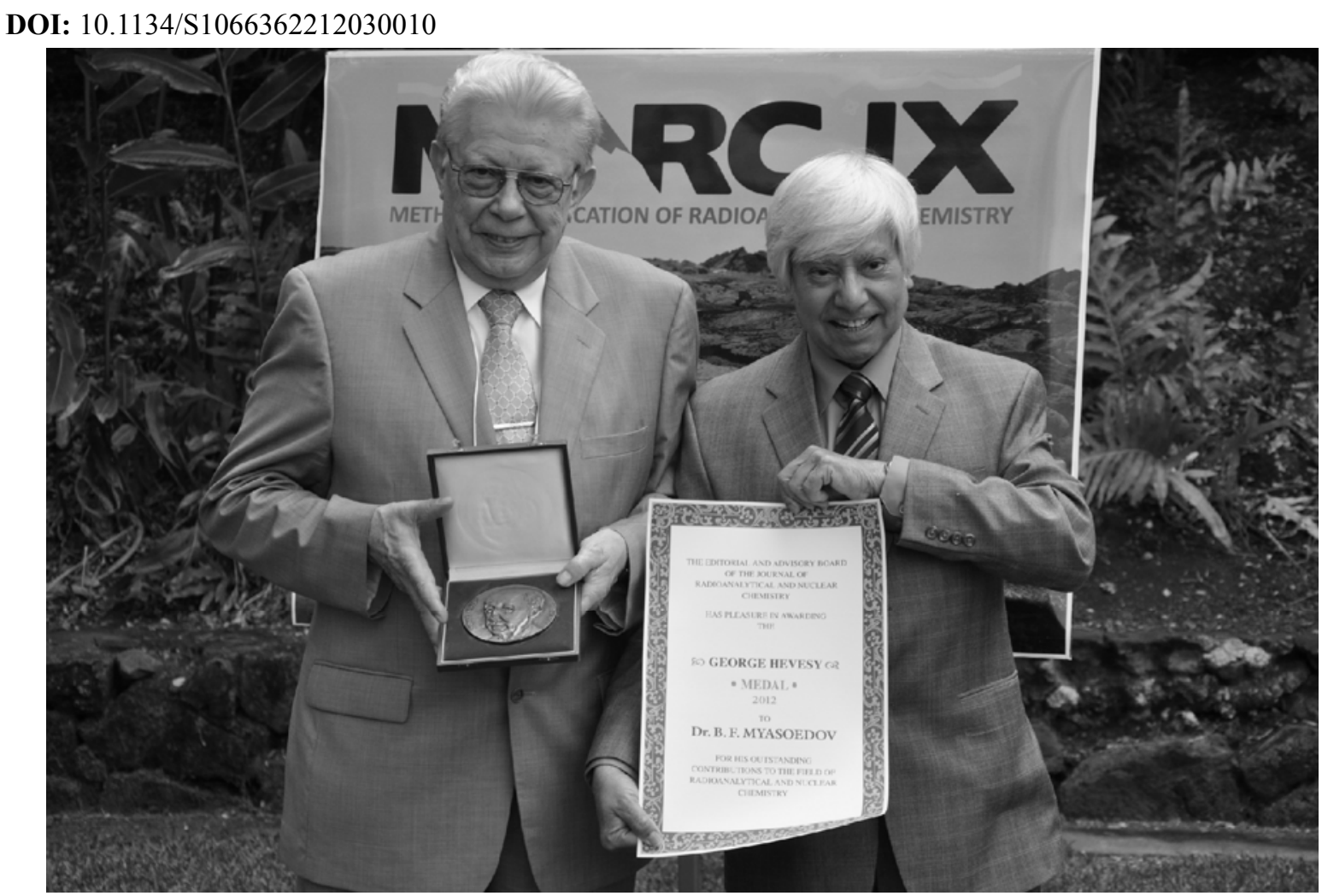

Acad. B. F. Myasoedov (left) with the Hevesy Medal presented to him. To the right: Chair of the Hevesy Medal Award Selection Panel 2012, ICAA/MTAA President, Prof. A. Chatt.

A premier international award, G. Hevesy Medal, was presented to Editor-in-Chief of Radiokhimiyal Radiochemistry journal, Acad. B.F. Myasoedov at the Ninth International Conference on Methods and Applications of Radioanalytical Chemistry (MARC-IX), held in the United States during March 25-30, 2012.

The medal is named after G. Hevesy (1885-1966), who received the Nobel Prize for Chemistry in 1943 for his work on the use of isotopes and tracers in the study of chemical processes. The medal was established by Journal of Radioanalytical and Nuclear Chemistry and was awarded annually in the period 1968-1986 and then from 2000 till now for outstanding achievements in the fields of pure and applied nuclear and radiochemistry, in particular, applications to nuclear analytical chemistry. The award is adjudicated by the International Committee on Activation Analysis/Modern Trends in Activation Analysis (ICAA/MTAA).

Among Hevesy Medal Award recipients are such renowned scientists as A. Chatt, G. Choppin, D. Hoffman, and others. However, only one Russian scientist was awarded previously: Acad. I.P. Alimarin (1970), a prominent Soviet analytical chemist.

The Hevesy Medal Award Selection Panel, selecting Acad. B.F. Myasoedov, noted his outstanding contribution in the field of radiochemistry, including fundamental research on chemical properties of actinides, particularly in unusual oxidation states, development of rapid separation methods for actinides and fission products, and nuclear waste management.

The Hevesy Medal Award is the recognition of personal achievements of Acad. B. F. Myasoedov and of the international authority of Russian radiochemical science.

The Editorial Board of Radiokhimiya/Radiochemitry journal congratulates the Editor-in-Chief of the journal, Acad. B.F. Myasoedov, on his awarding with the Hevesy Medal and wishes him sound health, new scientific achievements, and wealth. 